\title{
OCENA ZASIĘGU EFEKTU BRZEGOWEGO W PŁYTACH HENCKY'EGO-BOLLE'A O WYBRANYCH WARUNKACH BRZEGOWYCH
}

\author{
Mykola Nagirniak
}

Wydział Budownictwa i Inżynierii Środowiska, Szkoła Główna Gospodarstwa Wiejskiego w Warszawie, Warszawa

\begin{abstract}
STRESZCZENIE
W pracy analizowano efekt brzegowy w teorii płyt. Rozpatrzono półpasmo płytowe i płyty prostokątne obciążone na brzegu swobodnym momentami skręcającymi $\hat{m}(\xi)=\frac{\hat{q}_{0} a}{\pi} \cos (\pi \xi)$ i obciążeniem poprzecznym $\hat{q}(\xi)=\hat{q}_{0} \sin (\pi \xi)$. Tego typu obciążenie nie wywołuje przemieszczeń i sił przekrojowych w płytach liczonych według teorii płyt cienkich. Efekt brzegowy pojawia się w przypadku płyty średniej grubości. W pracy uzyskano rozwiązania według teorii Hencky’ego-Bolle'a. Przedstawiono efekt brzegowy w paśmie płytowym i płytach prostokątnych. Zbadano zasięg zaburzeń wywołanych obciążeniem brzegu w półpaśmie oraz wpływ jednorodnych warunków brzegowych, danych na przeciwległych brzegach płyt prostokątnych, na zasięg efektu brzegowego. Wykazano, że rozwiązania półpasma i płyt prostokątnych przy ilorazie $\eta_{0}=\frac{b}{a}=1$ nie wiele się różnią, a przy $\eta_{0}=\frac{b}{a}=2$ zanikają, czyli w odległości dwóch szerokości płyty zanikają przemieszczenia i siły przekrojowe.
\end{abstract}

Słowa kluczowe: płyty Kirchhoffa, płyty Hencky’ego-Bolle’a, efekt brzegowy

\section{WSTĘP}

W mechanice tarcz, płyt, powłok i ciał 3D efekt brzegowy występuje głównie w przypadku niemożności ścisłego spełnienia warunków brzegowych (Konieczny i Woźniak 1967; Woźniak, 1967; Kaczmarek, 2003). W przypadku samorównoważnego obciążenia brzegu efekt ten jest też ściśle związany z zasadą de Saint-Venanta. W przypadku płyt siatkowych otrzymuje się cząstkowe równanie różniczkowe na ugięcie czwartego rzędu, co uniemożliwia spełnienia trzech warunków na brzegu płyty (Konieczny i Woźniak, 1967). Ten efekt brzegowy możemy zdecy- dowanie zmniejszyć, wprowadzając dodatkowe równanie, zwane równaniem efektu brzegowego.

Efekt brzegowy w teorii płyt badał Bolle (1974). W 1947 roku przedstawił on rozwiązanie swobodnej, izotropowej i jednorodnej płyty kołowej obciążonej na brzegu momentem skręcającym i siłą poprzeczną w ten sposób, że według teorii Kirchhoffa otrzymuje się rozwiązanie zerowe, zaś według teorii płyt średniej grubości - niezerowe (Woźniak, 2001). W tym rozwiązaniu zakłada się, że ugięcie w środku płyty jest zerowe.

$凶_{\text {mnagirniak@gmail.com }}$ 
Nagirniak, M. (2019). Ocena zasięgu efektu brzegowego w płytach Hencky'ego-Bolle'a o wybranych warunkach brzegowych. Acta Sci. Pol. Architectura 18 (2), 93-105, DOI: 10.22630/ASPA.2019.18.2.26

Rozpatrzmy płyty izotropowe i jednorodne o stałych sztywnościach (rys. 1), obciążone na brzegu swobodnym momentami skręcającymi i obciążeniem poprzecznym.

$\hat{q}(\xi)=\hat{q}_{0} \sin (\pi \xi), \hat{m}(\xi)=\frac{\hat{q}_{0} a}{\pi} \cos (\pi \xi)$

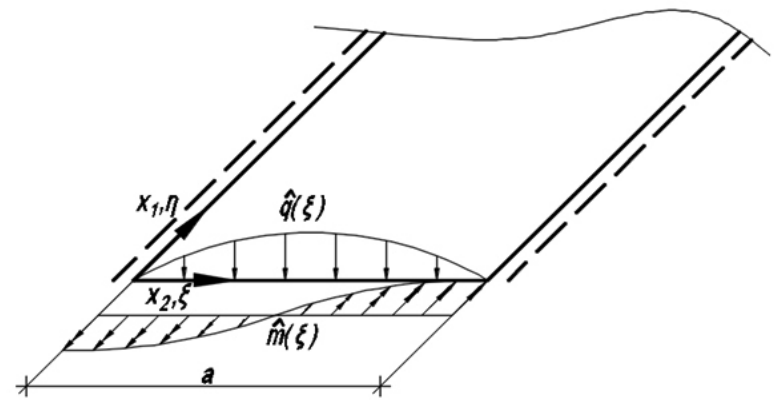

c

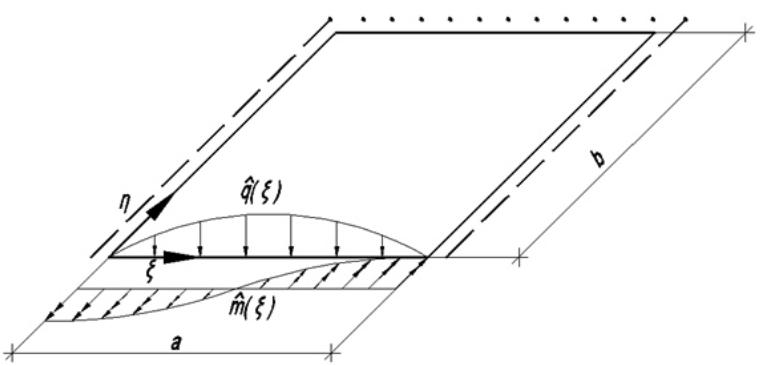

Celem pracy jest analiza płyt izotropowych pokazanych na rysunku 1 , wyznaczenie zasięgu zaburzeń przemieszczeń i sił przekrojowych wywołanych obciążeniami na brzegach płyty $(\eta=0)$ oraz wpływu przeciwległego brzegu $\left(\eta_{0}=\frac{b}{a}\right)$ na te zaburzenia.

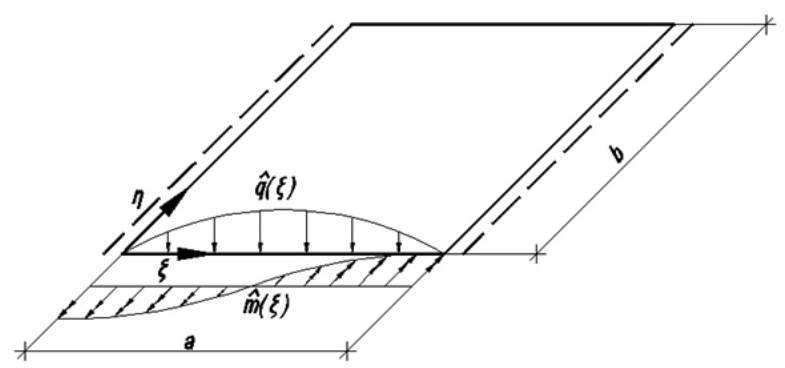

d

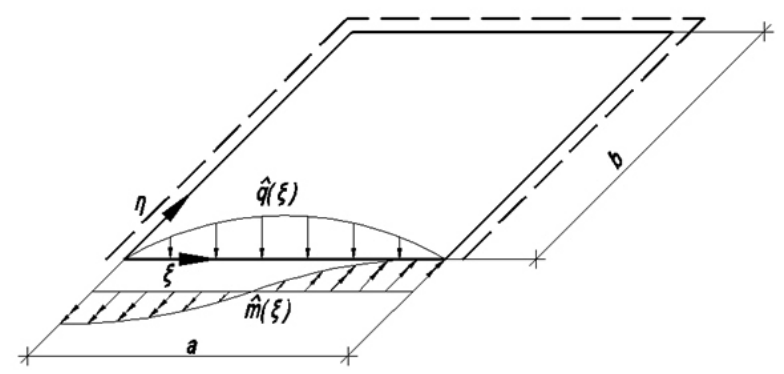

e

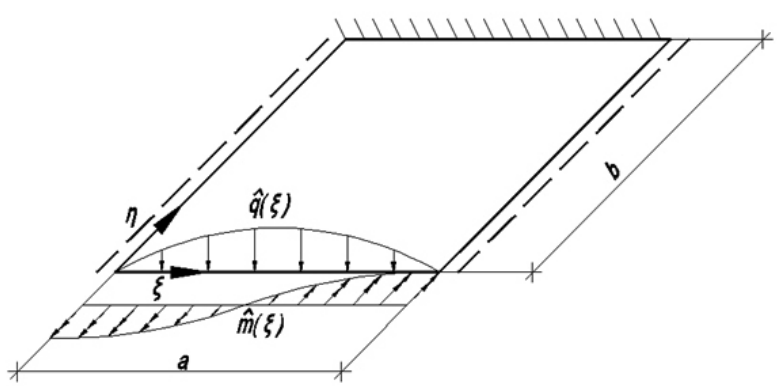

$$
\eta=\frac{x_{1}}{a}, \xi=\frac{x_{2}}{a}, \eta_{0}=\frac{b}{a}
$$

Rys. 1. a - półpasmo płytowe, b, c, d, e - płyty prostokątne o przeciwległym brzegu odpowiednio: swobodnym, swobodnie podpartym, przegubowym i utwierdzonym

Fig. 1. a-half-band plate, $c, d, e-$ rectangular plates with opposite edge respectively: free, freely supported, jointed and fixed 


\section{RÓWNANIA RÓŻNICZKOWE I WARUNKI BRZEGOWE TEORII PŁYT KIRCHHOFFA}

Podstawowe równanie teorii Kirchhoffa płyt o symetrycznej niejednorodności poprzecznej o stałej sztywności zapisujemy w postaci

$D \nabla^{4} w=q$

w której sztywność płyty $D$ zapiszemy wzorem

$D=\int_{-h_{2}}^{h_{1}} \frac{z^{2} E(z)}{1-v(z)^{2}} d z=\frac{E h^{3}}{12\left(1-v^{2}\right)}$, gdzie $h_{1}=h_{2}=\frac{h}{2}$

Na brzegu płyty mamy cztery dopuszczalne kombinacje warunków brzegowych (Woźniak, 2001). Na brzegu swobodnym $(\eta=0$, rys. 1$)$ mamy

$M_{n}=\hat{M}_{n}, V_{n}=\hat{V}_{n}$

przy czym zastępcza siła poprzeczna (tzw. siła Kirchhoffa) jest zdefiniowana wzorem

$V_{n}=Q_{n}+\frac{\partial M_{n s}}{\partial s}$

Na brzegu przegubowo podpartym (rys. $1 \mathrm{~d}, \eta=\eta_{0}$ ) niejednorodne warunki brzegowe zapisujemy w postaci

$M_{n}=\hat{M}_{n}, w=\hat{w}$

a na brzegu utwierdzonym (rys. 1e, $\eta=\eta_{0}$ ) następująco

$\frac{\partial w}{\partial n}=\phi_{s}=\hat{\phi}_{s}, w=\hat{w}^{*}$

Występujące we wzorach (4), (6) i (7) wielkości opatrzone daszkiem są danymi funkcjami na brzegu płyty, wielkość $\hat{\phi}_{s}$ jest danym kątem obrotu o wektorze stycznym do brzegu.
Warunki brzegowe pokazane na rysunku $1 \mathrm{c}(\eta=$ $=\eta_{0}$ ) nazywamy warunkami brzegu swobodnie podpartego, wtedy gdy spełnione są warunki

$w=\hat{w}, M_{n}=\hat{M}_{n s}=\hat{M}_{s}$

Warunki ze wzoru (8) nie są możliwe do spełnienia $w$ teorii płyt cienkich, ale występują $w$ teorii płyt średniej grubości.

\section{RÓWNANIA RÓŻNICZKOWE TEORII PŁYT HENCKY'EGO-BOLLE'A}

Podstawowe równanie teorii Hencky'ego-Bolle'a płyt o symetrycznej niejednorodności poprzecznej o stałej sztywności, przy pominięciu obciążeń stycznych, sił i momentów masowych oraz naprężeń $\sigma_{33}$, zapiszemy w postaci (Woźniak, 2001)

$D \nabla^{4} w=p_{3}-\frac{D}{K} \nabla^{2} p_{3}$

$\nabla^{2} \psi-\frac{2 K}{D\left(1-v_{D}\right)} \psi=0$

w których oznaczono

$\psi=\epsilon^{\alpha \beta} \phi_{\alpha, \beta}$

$K=k \int_{-h_{2}}^{h_{1}} G_{3}(z) d z, v_{D}=\frac{1}{D} \int_{-h_{2}}^{h_{1}} \frac{z^{2} v(z) E(z)}{1-v(z)^{2}} d z$

gdzie:

$\epsilon^{\alpha \beta}$ - symbol permutacyjny Ricciego,

$G_{3}-$ moduł Kirchhoffa,

$h$ - wysokość płyty,

$k$ - współczynnik ścinania wyznaczany ze wzorów danych w pracy Jemielity (2002).

\footnotetext{
${ }^{*}$ W polskich i anglojęzycznych pracach z teorii płyt Kirchhoffa brzeg, na którym spełnione są warunki (wzór 6), nazywany jest swobodnie podpartym (ang. simply supported). Jest to nazwa błędna. Jeśli na brzegu płyty cienkiej jest spełniony warunek $w(s)=0$, to też $\frac{\partial w}{\partial s}=0$, a zatem jest to warunek brzegu przegubowo podpartego (por. wzory $8,18 \mathrm{i} 19$ ).
} 
Kąty obroty $\phi_{\alpha}$ wyznaczamy ze wzorów

$$
\phi_{\alpha}=w_{, \alpha}+\frac{D\left(1-v_{D}\right)}{2 K}\left[\epsilon_{\alpha}{ }^{\beta} \psi_{, \beta}+\frac{2}{1-v_{D}} \nabla^{2} w_{, \alpha}+\frac{2 p_{3, \alpha}}{\left(1-v_{D}\right) K}\right]
$$

Momenty zginające, skręcające i siły poprzeczne wyznaczamy ze wzorów

$$
\begin{aligned}
& M_{\alpha \beta}=D\left[\left(1-v_{D}\right) \kappa_{\alpha \beta}+v_{D} \kappa^{\gamma}{ }_{\gamma} \delta_{\alpha \beta}\right] \\
& Q_{\alpha}=K \chi_{\alpha}
\end{aligned}
$$

w których

$$
\kappa_{\alpha \beta}=-\frac{1}{2}\left(\phi_{\alpha, \beta}+\phi_{\beta, \alpha}\right), \chi_{\alpha}=w_{, \alpha}-\phi_{\alpha}
$$

gdzie: $\delta_{\alpha \beta}-$ delta Kroneckera.

Zauważmy, że teoria Hencky'ego-Bolle'a umożliwia spełnienie ośmiu kombinacji trzech warunków na danym brzegu płyty, np. takich jak:

1. Brzeg swobodny (rys. 1) przy $\eta=0$

$Q_{n}=\hat{Q}_{n}, M_{n}=\hat{M} n, M_{n s}=\hat{M}_{s}$

2. Brzeg swobodnie podparty (rys. 1c) przy $\eta_{0}=\frac{b}{a}$ $w=\hat{w}, M_{n}=\hat{M}_{n}, M_{n s}=\hat{M}_{s}$

3. Brzeg przegubowo podparty (rys. 1d) przy $\eta_{0}=\frac{b}{a}$ $w=\hat{w}, M_{n}=\hat{M}_{n}, \phi_{s}=\hat{\phi}_{s}$

4. Brzeg utwierdzony (rys. 1e) przy $\eta_{0}=\frac{b}{a}$ $w=\hat{w}, \phi_{n}=\hat{\phi}_{n}, \phi_{s}=\hat{\phi}_{s} \quad$ (por. wzór 7)

\section{ROZWIAZANIA WED}

Zauważmy, że na brzegu $\eta=0$ warunki brzegowe, dla wszystkich płyt $\mathrm{z}$ rysunku 1 , zapisujemy w postaci

$$
M_{n}(\xi, 0)=0, V_{n}(\xi, 0)=-\hat{q}-\frac{1}{a} \frac{d \hat{m}(\xi)}{d \xi}=0
$$

W przypadku półpasma, przy $\eta=\infty$, wielkości statyczne i kinematyczne są równe zeru, a warunki brzegowe przy $\eta=\eta_{0}$ dla płyt prostokątnych są też zerowe, więc przy braku obciążeń na powierzchni płyt otrzymujemy rozwiązania zerowe, tj. przemieszczenia i siły przekrojowe są równe zeru. Możemy powiedzieć, że płyta Kirchhoffa „nie widzi” tego typu samorównoważnego obciążenia brzegu płyty.

\section{ROZWIĄZANIE WEDŁUG TEORII HENCKY'EGO- -BOLLE'A}

\section{Półpasmo płytowe}

Rozpatrujemy pasmo płytowe przegubowo podparte na brzegach $\xi=0$ i $\xi=1$, obciążone na brzegu swobodnym momentem skręcającym i siłą poprzeczną o postaci (rys. 1a)

$\hat{q}(\xi)=q_{0} \sin (\pi \xi)$

$\hat{m}(\xi)=q_{0} \frac{a}{\pi} \cos (\pi \xi)$

$\xi=\frac{x_{2}}{a}, \eta=\frac{x_{1}}{a}$

Warunki brzegowe zapisujemy w postaciach

$$
\begin{aligned}
& M_{11}(0, \xi)=0, M_{12}(0, \xi)=-\hat{m}(\xi)=-\frac{\hat{q}_{0} a}{\pi} \cos (\pi \xi), \\
& Q_{1}=-\hat{q}(\xi)=-\hat{q}_{0} \sin (\pi \xi)
\end{aligned}
$$

Rozwiązanie jednorodnego układu równań (9) i (10) dla płyty izotropowej przewidujemy w postaci

$w(\xi, \eta)=e^{-\pi \eta}\left(C_{1}+C_{2} \pi \eta\right) \sin \pi \xi$

$\psi(\xi, \eta)=\frac{C_{3}}{a^{2}} e^{-\tau \eta} \cos (\pi \xi)$ 
gdzie $\tau=\pi \sqrt{1+\frac{10}{\pi^{2} \delta^{2}}}, \delta=\frac{h}{a}$

Po uwzględnieniu warunków brzegowych (wzór 25) otrzymamy następujące wzory na ugięcie $w(\xi, \eta)$ i siły przekrojowe

$w=-\frac{2 a^{3} e^{-\pi \eta} q_{0}\left(2 \pi^{2}+\pi^{3} \eta(v-1)-\tau^{2}(1+v)-\pi \tau(3+\tau \eta(v-1)+v)\right)}{D \pi^{2}\left(\pi^{2}-\tau^{2}\right)(v-1)(\pi(v-1)+\tau(3+v))} \sin (\pi \xi)$

$M_{11}=-\frac{2 a e^{-(\pi+\tau) \eta} q_{0}\left(e^{\pi \eta} \tau(3+v)+e^{\tau \eta}\left(\pi^{2} \eta(v-1)-\tau(3+\pi \eta(v-1)+v)\right)\right)}{(\pi-\tau)(\pi(v-1)+\tau(3+v))} \sin (\pi \xi)$

$Q_{1}=-\frac{e^{-(\pi+\tau) n} q_{0}\left(4 e^{\tau \eta} \pi+e^{\pi n}(\pi+\tau)(3+v)\right)}{\pi(v-1)+\tau(3+v)} \sin (\pi \xi)$

gdzie sztywność na zginanie płyty $D$ określono wzorem $D=\frac{a^{3} E \delta^{3}}{12\left(1-v^{2}\right)}$

Na rysunkach 2-4 przedstawiono wartości ugięć, kątów obrotu, momentu zginającego i siły poprzecznej w środku płyty $(\xi=0,5)$ dla $v=0$ i $v=0,5 ; \delta=0,1$.

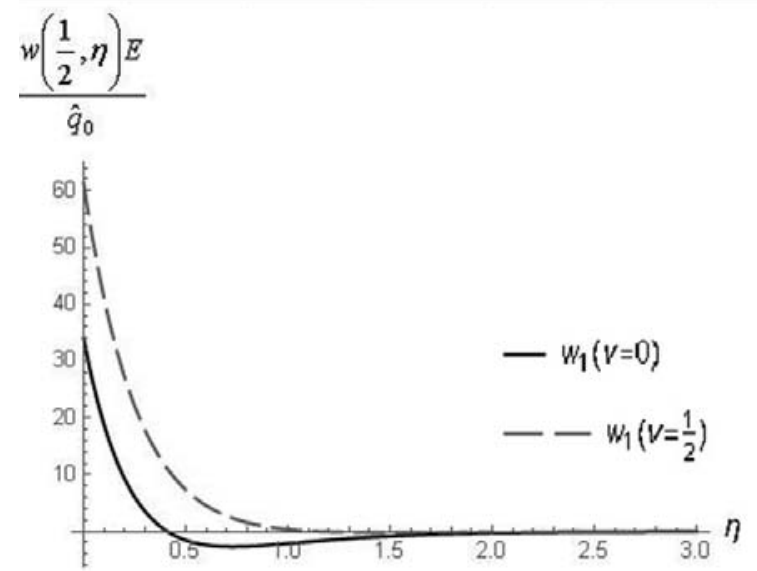

Rys. 2. Wykres ugięcia płyty $\frac{w\left(\frac{1}{2}, \eta\right) E}{\hat{q}_{0}}$

Fig. 2. Graph of deflection of plate $\frac{w\left(\frac{1}{2}, \eta\right) E}{\hat{q}_{0}}$

$$
\frac{M_{11}\left(\frac{1}{2}, \eta\right)}{a \hat{q}_{0}}
$$

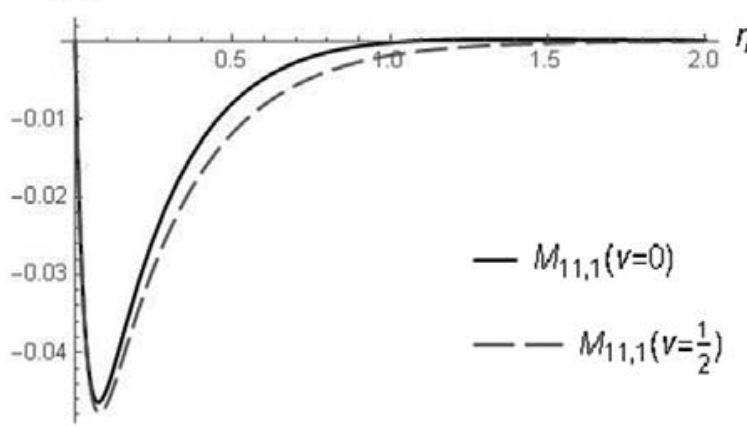

Rys. 3. Wykres momentów zginających $\frac{M_{11}\left(\frac{1}{2}, \eta\right)}{a \hat{q}_{0}}$

Fig. 3. Graph of the bending moments $\frac{M_{11}\left(\frac{1}{2}, \eta\right)}{a \hat{q}_{0}}$ 
$\frac{Q_{1}\left(\frac{1}{2}, \eta\right)}{\hat{q}_{0}}$

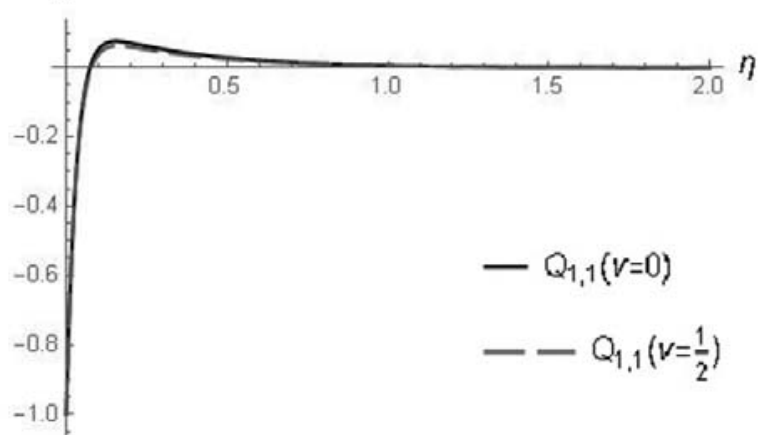

Rys. 4. Wykres sily poprzecznej $\frac{Q_{1}\left(\frac{1}{2}, \eta\right)}{\hat{q}_{0}}$

Fig. 4. Graph of transverse force $\frac{Q_{1}\left(\frac{1}{2}, \eta\right)}{\hat{q}_{0}}$

Widoczne jest, że w odległości $\eta=1$ bardzo szybko zanikają: przemieszczenie, moment zginający i siła poprzeczna. Moment zginający $M_{11}$ osiąga wartości maksymalne przy brzegu płyty w odległości $\eta=0,07$.

\section{Płyty prostokątne}

Rozpatrzmy efekt brzegowy w płytach prostokątnych przedstawionych na rysunku 1 . Jednorodne warunki brzegowe przy $\eta=\frac{b}{a}=\eta_{0}$ przyjmują postacie:

- brzeg swobodny (rys. 1b)

$M_{11}\left(\xi, \eta_{0}\right)=0, M_{12}\left(\xi, \eta_{0}\right)=0, Q_{1}\left(\xi, \eta_{0}\right)=0$

- brzeg swobodnie podparty (rys. 1c)

$$
w\left(\xi, \eta_{0}\right)=0, M_{11}\left(\xi, \eta_{0}\right)=0, M_{12}\left(\xi, \eta_{0}\right)=0
$$

- brzeg przegubowy (rys. 1d) $w\left(\xi, \eta_{0}\right)=0, M_{11}\left(\xi, \eta_{0}\right)=0, \phi_{2}\left(\xi, \eta_{0}\right)=0$

- brzeg utwierdzony (rys. 1e)

$w\left(\xi, \eta_{0}\right)=0, \phi_{1}\left(\xi, \eta_{0}\right)=0, \phi_{2}\left(\xi, \eta_{0}\right)=0$

Rozwiązanie równań różniczkowych (9) i (10) poszukujemy w postaci

$w=\left(C_{1} e^{-\pi \eta}+C_{2} e^{-\pi \eta}+C_{3} e^{\pi \eta}+C_{4} e^{\pi \eta}\right) \sin (\pi \xi)$

$\psi=\frac{C_{6} e^{-\tau \eta}+C_{5} e^{\tau \eta}}{a^{2}} \cos (\pi \xi)$

Momenty i siły poprzeczne wyznaczamy ze wzorów (14) i (15). Korzystając z warunków brzegowych (33)-(36), wyznaczono wzory na przemieszczenia i sily przekrojowe. Wyniki przedstawiono $\mathrm{w}$ postaci wykresów dla wartości $\eta_{0}=1 / 2,1,2,3 ; v=0, v=0,5$; $\delta=0,1$.

$\mathrm{Na}$ rysunkach 5-20 wprowadzono następujące oznaczenia na przemieszczenia płyt: $\mathrm{z} w_{1}$ (rys. 1a), $w_{2}$ (rys. 1b), $w_{3}$ (rys. 1c), $w_{4}$ (rys. 1d), $w_{5}$ (rys. 1e), a na moment zginający $M_{11}$ odpowiednio: $M_{11, k}, k=1,2$, $3,4,5$.

Na rysunkach 5-8 przedstawiono wykresy bezwymiarowych wartości przemieszczeń półpasma $\frac{w_{1}\left(\frac{1}{2}, \eta\right) E}{\hat{q}_{0}} \mathrm{w}$ porównaniu $\mathrm{z}$ wartościami płyt prostokątnych dla $\eta_{0}=1 / 2,1,2,3: \frac{w_{2}\left(\frac{1}{2}, \eta\right) E}{\hat{q}_{0}}($ rys. 5), $\frac{w_{3}\left(\frac{1}{2}, \eta\right) E}{\hat{q}_{0}}\left(\right.$ rys. 6),$\frac{w_{4}\left(\frac{1}{2}, \eta\right) E}{\hat{q}_{0}}$ (rys. 7), $\frac{w_{5}\left(\frac{1}{2}, \eta\right) E}{\hat{q}_{0}}$ (rys. 8), przy $v=0$. Na rysunkach $9-12$ analogiczne wykresy przy $v=0,5$. 


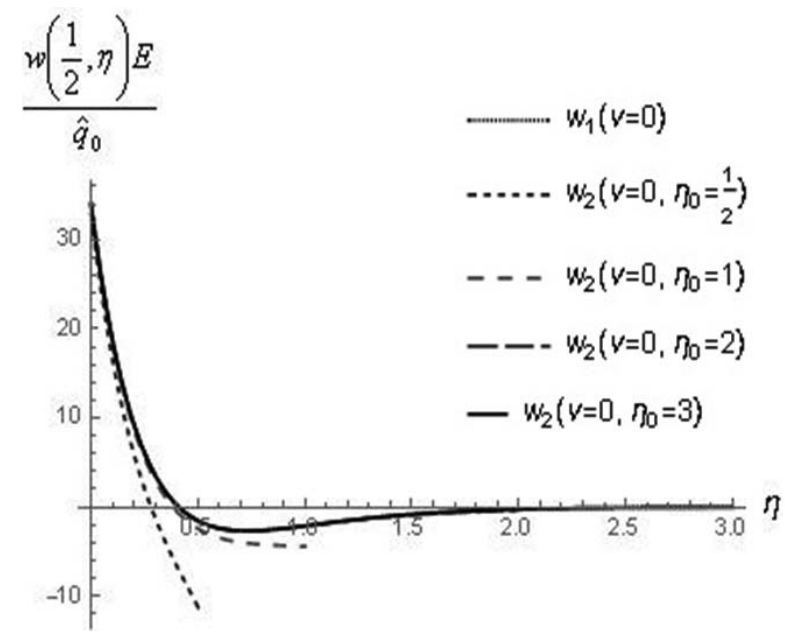

Rys. 5. Wykres ugięcia płyty $\frac{w\left(\frac{1}{2}, \eta\right) E}{\hat{q}_{0}}$

Fig. 5. Graph of deflection of plate $\frac{w\left(\frac{1}{2}, \eta\right) E}{\hat{q}_{0}}$

$\frac{w\left(\frac{1}{2}, \eta\right) E}{\hat{q}_{0}}$

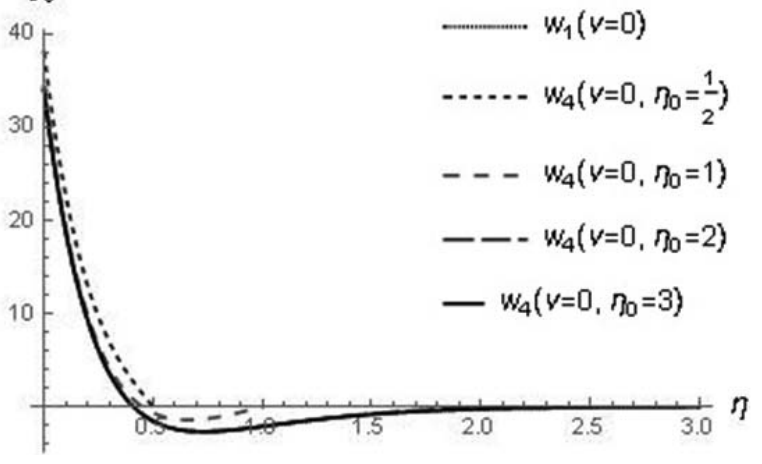

Rys. 7. Wykres ugięcia płyty $\frac{w\left(\frac{1}{2}, \eta\right) E}{\hat{q}_{0}}$

Fig. 7. Graph of deflection of plate $\frac{w\left(\frac{1}{2}, \eta\right) E}{\hat{q}_{0}}$

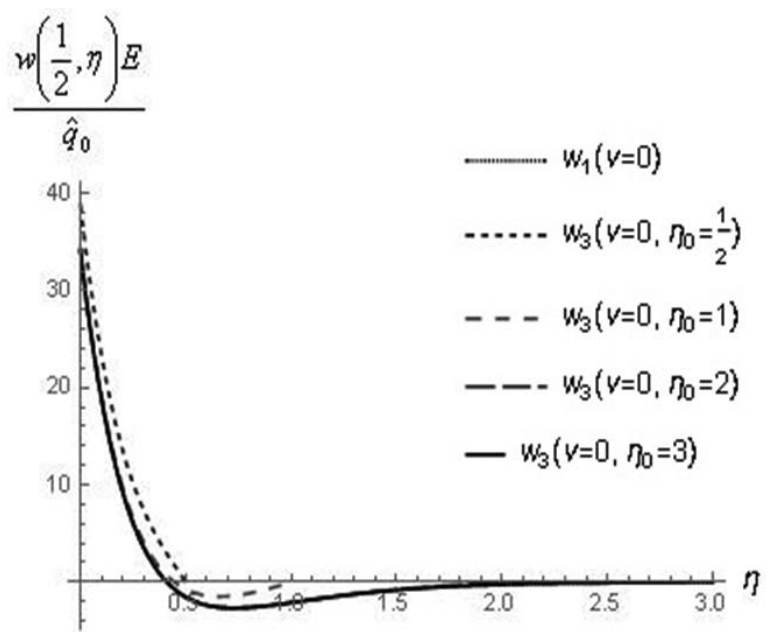

Rys. 6. Wykres ugięcia płyty $\frac{w\left(\frac{1}{2}, \eta\right) E}{\hat{q}_{0}}$

Fig. 6. Graph of deflection of plate $\frac{w\left(\frac{1}{2}, \eta\right) E}{\hat{q}_{0}}$

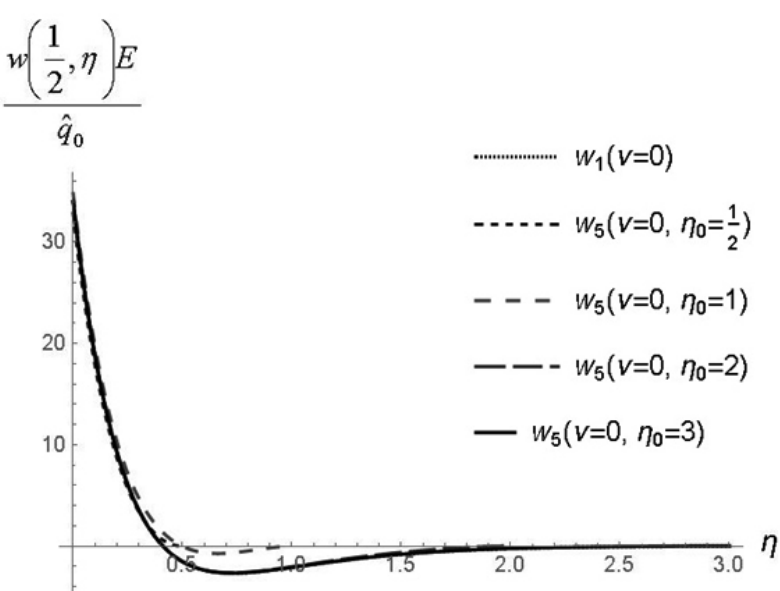

Fig. 8. Graph of deflection of plate $\frac{w\left(\frac{1}{2}, \eta\right) E}{\hat{q}_{0}}$ 


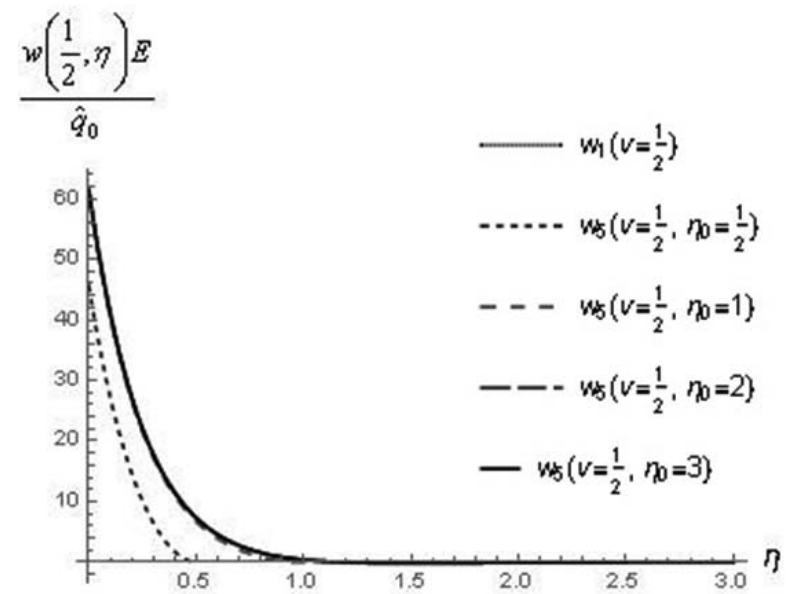

Rys. 9. Wykres ugięcia płyty $\frac{w\left(\frac{1}{2}, \eta\right) E}{\hat{q}_{0}}$

Fig. 9. Graph of deflection of plate $\frac{w\left(\frac{1}{2}, \eta\right) E}{\hat{q}_{0}}$

$\frac{w\left(\frac{1}{2}, \eta\right) E}{\hat{q}_{0}}$

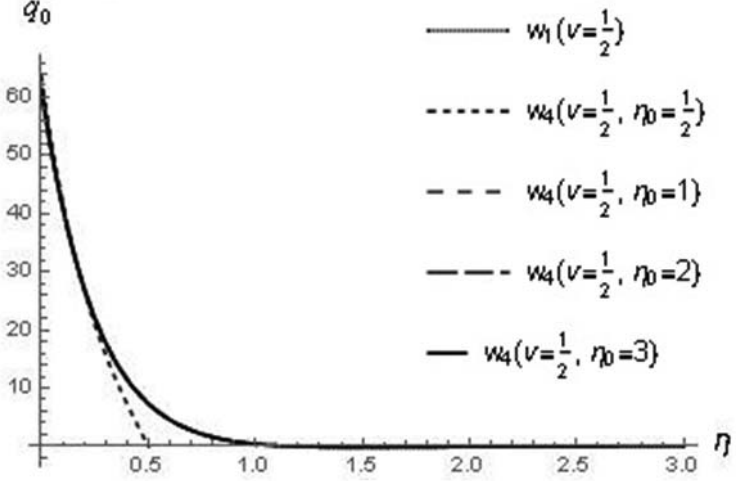

Rys. 11. Wykres ugięcia płyty $\frac{w\left(\frac{1}{2}, \eta\right) E}{\hat{q}_{0}}$

Fig. 11. Graph of deflection of plate $\frac{w\left(\frac{1}{2}, \eta\right) E}{\hat{q}_{0}}$

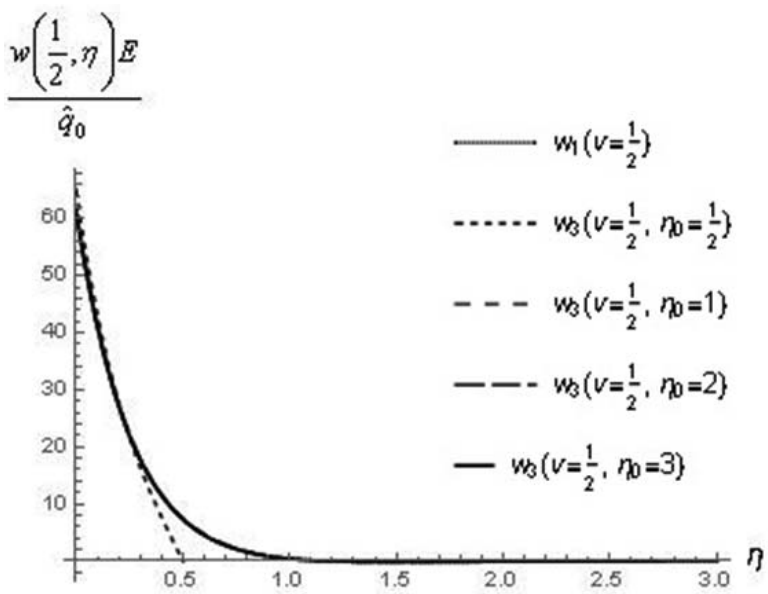

Rys. 10. Wykres ugięcia płyty $\frac{w\left(\frac{1}{2}, \eta\right) E}{\hat{q}_{0}}$

Fig. 10. Graph of deflection of plate $\frac{w\left(\frac{1}{2}, \eta\right) E}{\hat{q}_{0}}$

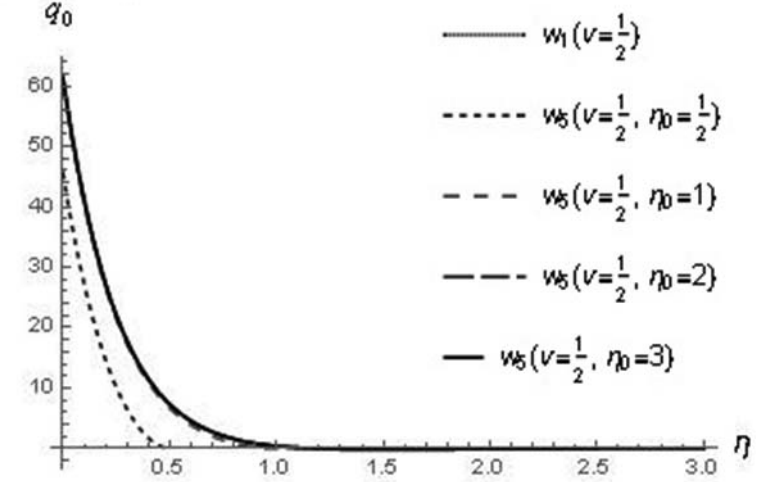

Rys. 12. Wykres ugięcia płyty $\frac{w\left(\frac{1}{2}, \eta\right) E}{\hat{q}_{0}}$

Fig. 12. Graph of deflection of plate $\frac{w\left(\frac{1}{2}, \eta\right) E}{\hat{q}_{0}}$ 
Nagirniak, M. (2019). Ocena zasięgu efektu brzegowego w płytach Hencky'ego-Bolle'a o wybranych warunkach brzegowych. Acta Sci. Pol. Architectura 18 (2), 93-105, DOI: 10.22630/ASPA.2019.18.2.26

Na rysunkach 13-20 przedstawiono, analogiczne do prezentowanych wykresów przemieszczeń, wykresy momentu zginającego $\frac{M_{11}\left(\frac{1}{2}, \eta\right)}{E \hat{q}_{0}}$ dla $v=0$ (rys. 13-16), a dla $v=0,5$ na rysunkach 17-20.

$\frac{M_{11}\left(\frac{1}{2}, \eta\right)}{a \hat{q}_{0}}$

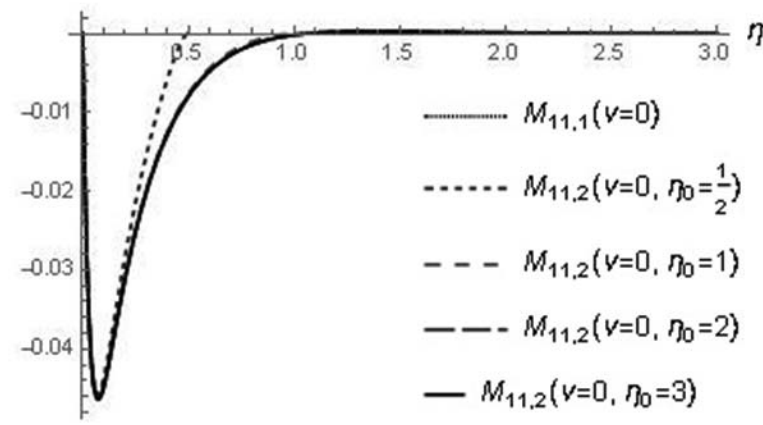

Rys. 13. Wykres momentów zginających $\frac{M_{11}\left(\frac{1}{2}, \eta\right)}{a \hat{q}_{0}}$

Fig. 13. Graph of the bending moments $\frac{M_{11}\left(\frac{1}{2}, \eta\right)}{a \hat{q}_{0}}$

$\frac{M_{11}\left(\frac{1}{2}, \eta\right)}{a \hat{q}_{0}}$

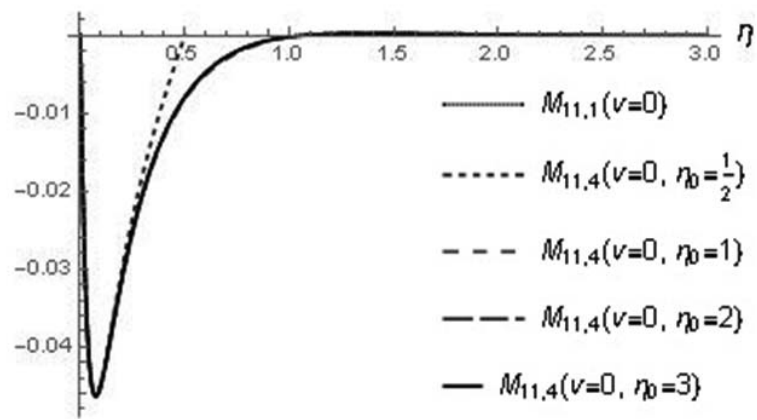

Rys. 15. Wykres momentów zginających $\frac{M_{11}\left(\frac{1}{2}, \eta\right)}{a \hat{q}_{0}}$

Fig. 15. Graph of the bending moments $\frac{M_{11}\left(\frac{1}{2}, \eta\right)}{a \hat{q}_{0}}$

$$
\frac{M_{11}\left(\frac{1}{2}, \eta\right)}{a \hat{q}_{0}}
$$

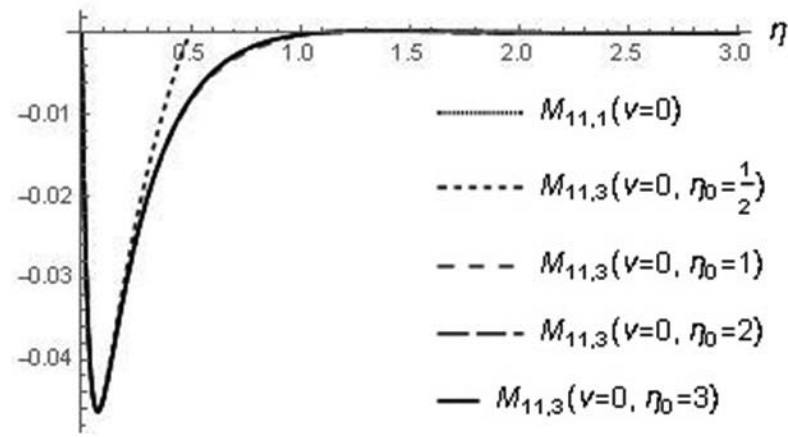

Rys. 14. Wykres momentów zginających $\frac{M_{11}\left(\frac{1}{2}, \eta\right)}{a \hat{q}_{0}}$

Fig. 14. Graph of the bending moments $\frac{M_{11}\left(\frac{1}{2}, \eta\right)}{a \hat{q}_{0}}$

$$
\frac{M_{11}\left(\frac{1}{2}, \eta\right)}{a \hat{q}_{0}}
$$

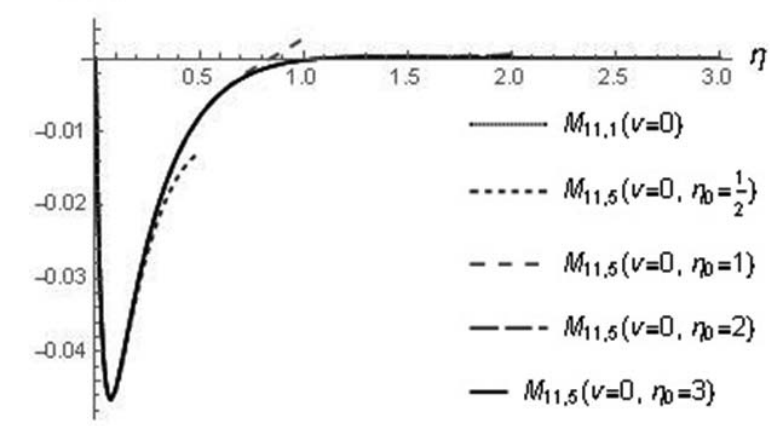

Rys. 16. Wykres momentów zginających $\frac{M_{11}\left(\frac{1}{2}, \eta\right)}{a \hat{q}_{0}}$

Fig. 16. Graph of the bending moments $\frac{M_{11}\left(\frac{1}{2}, \eta\right)}{a \hat{q}_{0}}$ 


$$
\frac{M_{11}\left(\frac{1}{2}, \eta\right)}{a \hat{q}_{0}}
$$

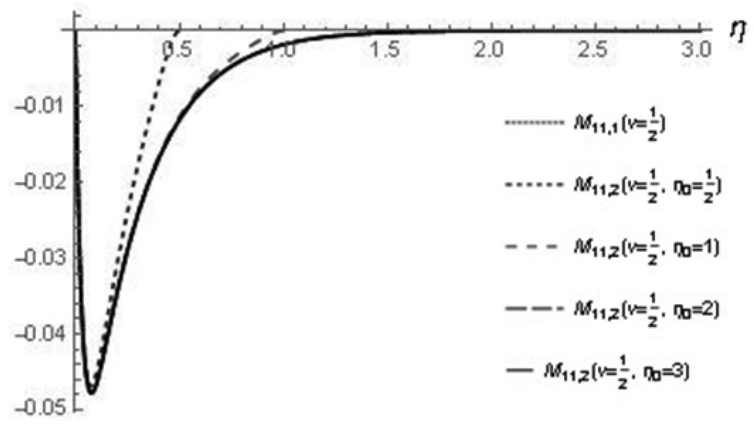

Rys. 17. Wykres momentów zginających $\frac{M_{11}\left(\frac{1}{2}, \eta\right)}{a \hat{q}_{0}}$

Fig. 17. Graph of the bending moments $\frac{M_{11}\left(\frac{1}{2}, \eta\right)}{a \hat{q}_{0}}$

$\frac{M_{11}\left(\frac{1}{2}, \eta\right)}{a \hat{q}_{0}}$

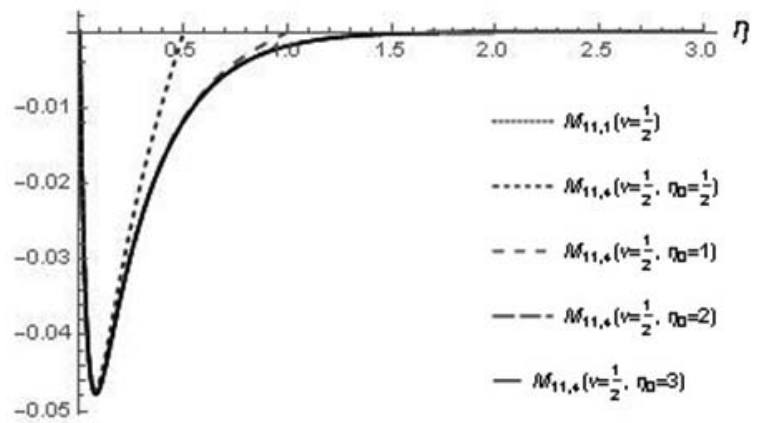

Rys. 19. Wykres momentów zginających $\frac{M_{11}\left(\frac{1}{2}, \eta\right)}{a \hat{q}_{0}}$

Fig. 19. Graph of the bending moments $\frac{M_{11}\left(\frac{1}{2}, \eta\right)}{a \hat{q}_{0}}$

$$
\frac{M_{11}\left(\frac{1}{2}, \eta\right)}{a \hat{q}_{0}}
$$

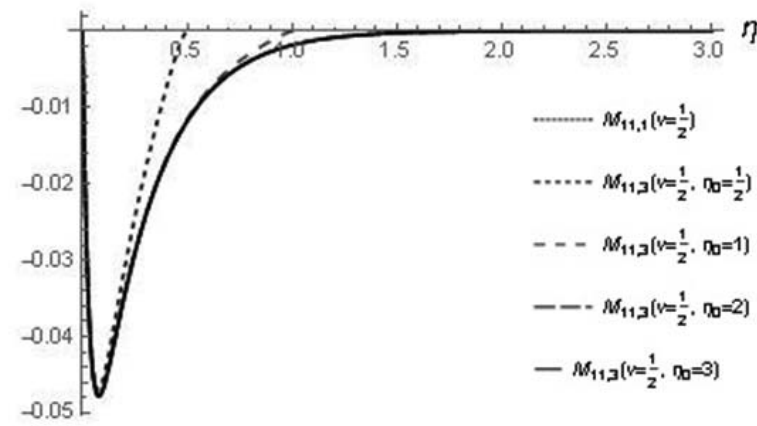

Rys. 18. Wykres momentów zginających $\frac{M_{11}\left(\frac{1}{2}, \eta\right)}{a \hat{q}_{0}}$

Fig. 18. Graph of the bending moments $\frac{M_{11}\left(\frac{1}{2}, \eta\right)}{a \hat{q}_{0}}$

$$
\frac{M_{11}\left(\frac{1}{2}, \eta\right)}{a \hat{q}_{0}}
$$

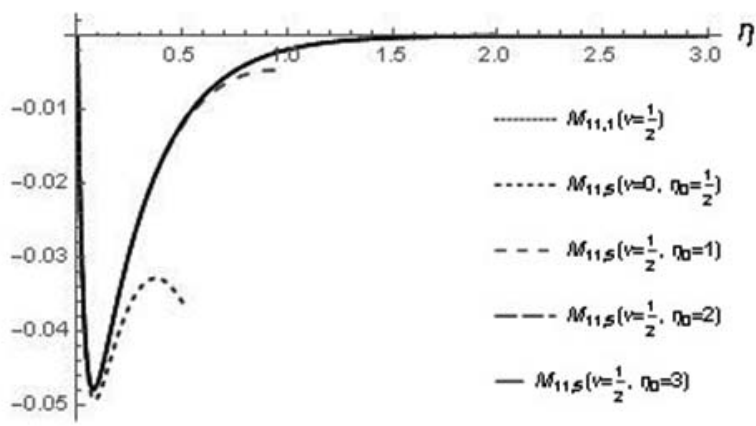

Rys. 20. Wykres momentów zginających $\frac{M_{11}\left(\frac{1}{2}, \eta\right)}{a \hat{q}_{0}}$

Fig. 20. Graph of the bending moments $\frac{M_{11}\left(\frac{1}{2}, \eta\right)}{a \hat{q}_{0}}$ 
Nagirniak, M. (2019). Ocena zasięgu efektu brzegowego w płytach Hencky'ego-Bolle'a o wybranych warunkach brzegowych. Acta Sci. Pol. Architectura 18 (2), 93-105, DOI: 10.22630/ASPA.2019.18.2.26

W tabeli 1 przedstawiono wartości maksymalnych ugięć $\frac{w\left(\frac{1}{2}, 0\right) E}{\hat{q}_{0}}$ dla $\eta_{0}=1 / 2,1,2,3$ i różnice procentowe $\frac{w_{k}-w_{1}}{w_{1}} \cdot 100$, a w tabeli 2 wartości maksymalnych momentów $\frac{M_{11}\left(\frac{1}{2}, \eta_{\text {ext }}\right)}{a \hat{q}_{0}}$ dla $\eta_{0}=1 / 2,1,2,3$.

Tabela 1. Wartości maksymalnych ugięć

Table 1. Maximum deflection values

\begin{tabular}{|c|c|c|c|c|c|}
\hline $\begin{array}{l}\text { Plyta } \\
\text { Plate }\end{array}$ & $\eta$ & $\begin{array}{c}\frac{w\left(\frac{1}{2}, 0\right) E}{\hat{q}_{0}} \\
v=0\end{array}$ & $\%$ & $\begin{array}{c}\frac{w\left(\frac{1}{2}, 0\right) E}{\hat{q}_{0}} \\
v=0,5\end{array}$ & $\%$ \\
\hline $\begin{array}{l}w_{1} \\
\text { półpasmo } \\
\text { half-band }\end{array}$ & - & 34,0155 & 0 & 61,3557 & 0 \\
\hline \multirow{4}{*}{$w_{2}$} & 0,5 & 32,8304 & $-3,484$ & 62,4192 & 1,733 \\
\hline & 1 & 33,6585 & $-1,049$ & 61,3353 & $-0,033$ \\
\hline & 2 & 34,0124 & $-0,009$ & 61,3551 & $-0,001$ \\
\hline & 3 & 34,0155 & 0 & 61,3557 & 0,000 \\
\hline \multirow{4}{*}{$w_{3}$} & 0,5 & 38,085 & 11,963 & 63,7315 & 3,872 \\
\hline & 1 & 34,3941 & 1,113 & 61,5603 & 0,333 \\
\hline & 2 & 34,0169 & 0,004 & 61,3565 & 0,001 \\
\hline & 3 & 34,0155 & 0 & 61,3557 & 0,000 \\
\hline \multirow{4}{*}{$w_{4}$} & 0,5 & 32,8491 & $-3,429$ & 45,6308 & $-25,629$ \\
\hline & 1 & 34,7944 & 2,289 & 60,8941 & $-0,752$ \\
\hline & 2 & 34,0235 & 0,023 & 61,3582 & 0,004 \\
\hline & 3 & 34,0155 & 0 & 61,3557 & 0,000 \\
\hline \multirow{4}{*}{$w_{5}$} & 0,5 & 38,7803 & 14,007 & 65,0534 & 6,027 \\
\hline & 1 & 34,3488 & 0,979 & 61,5972 & 0,394 \\
\hline & 2 & 34,0162 & 0,002 & 61,3564 & 0,001 \\
\hline & 3 & 34,0155 & 0 & 61,3557 & 0,000 \\
\hline
\end{tabular}


Nagirniak, M. (2019). Ocena zasięgu efektu brzegowego w płytach Hencky'ego-Bolle’a o wybranych warunkach brzegowych. Acta Sci. Pol. Architectura 18 (2), 93-105, DOI: 10.22630/ASPA.2019.18.2.26

Tabela 2. Wartości ekstremalnych momentów

Table 2. Values of extreme moments

\begin{tabular}{|c|c|c|c|c|c|}
\hline $\begin{array}{l}\text { Plyta } \\
\text { Plate }\end{array}$ & $\eta$ & $\begin{array}{c}\frac{M_{11}\left(\frac{1}{2}, \eta_{\text {ext }}\right)}{a \hat{q}_{0}} \\
v=0\end{array}$ & $\eta_{\text {ext }}$ & $\begin{array}{c}\frac{M_{11}\left(\frac{1}{2}, \eta_{\text {ext }}\right)}{a \hat{q}_{0}} \\
v=0,5\end{array}$ & $\eta_{\text {ext }}$ \\
\hline $\begin{array}{l}w_{1} \\
\text { półpasmo } \\
\text { half-band }\end{array}$ & - & $-0,0463$ & 0,0735 & $-0,0477$ & 0,0775 \\
\hline \multirow{4}{*}{$w_{2}$} & 0,5 & $-0,0456$ & 0,0713 & $-0,0467$ & 0,0742 \\
\hline & 1 & $-0,0463$ & 0,0734 & $-0,0477$ & 0,0774 \\
\hline & 2 & $-0,0463$ & 0,0735 & $-0,0477$ & 0,0775 \\
\hline & 3 & $-0,0463$ & 0,0735 & $-0,0477$ & 0,0775 \\
\hline \multirow{4}{*}{$w_{3}$} & 0,5 & $-0,0461$ & 0,0727 & $-0,0470$ & 0,0750 \\
\hline & 1 & $-0,0464$ & 0,0736 & $-0,0477$ & 0,0775 \\
\hline & 2 & $-0,0463$ & 0,0735 & $-0,0477$ & 0,0775 \\
\hline & 3 & $-0,0463$ & 0,0735 & $-0,0477$ & 0,0775 \\
\hline \multirow{4}{*}{$w_{4}$} & 0,5 & $-0,0466$ & 0,0743 & $-0,0491$ & 0,0830 \\
\hline & 1 & $-0,0464$ & 0,0737 & $-0,0477$ & 0,0776 \\
\hline & 2 & $-0,0463$ & 0,0735 & $-0,0477$ & 0,0775 \\
\hline & 3 & $-0,0463$ & 0,0735 & $-0,0477$ & 0,0775 \\
\hline \multirow{4}{*}{$w_{5}$} & 0,5 & $-0,0461$ & 0,0725 & $-0,0468$ & 0,0745 \\
\hline & 1 & $-0,0464$ & 0,0736 & $-0,0477$ & 0,0775 \\
\hline & 2 & $-0,0463$ & 0,0735 & $-0,0477$ & 0,0775 \\
\hline & 3 & $-0,0463$ & 0,0735 & $-0,0477$ & 0,0775 \\
\hline
\end{tabular}

\section{WNIOSKI}

W pracy wyznaczono wartości przemieszczeń i sił przekrojowych dla różnych wartości $\delta=\frac{h}{a}$, a przedstawiono wyniki tylko dla $\delta=0,1$. Wyniki dla innych wartości $\delta$ mają taki sam charakter. Różnią się tylko wartościami. Dla cieńszych płyt wartości przemieszczeń i sił przekrojowych są większe, $\mathrm{z}$ tym że różnice w przemieszczeniach są zdecydowanie większe niż w siłach przekrojowych.

Wykazano, że rozwiązania półpasma i płyt prostokątnych przy ilorazie $\eta_{0}=\frac{b}{a}=1$ (rys. 1) nie wiele się różnią, a przy $\eta=\eta_{0}=\frac{b}{a}=2$ zanikają. Wpływ przeciwległego brzegu płyty na wartości przemieszczeń i sił przekrojowych przy $\eta=\eta_{0}=1$ można pominąć i przyjmować wartości przemieszczeń i sił przekrojowych jak dla półpasma.

Wpływ współczynnika Poissona na wartości ugięć jest znaczny, natomiast na wartości momentu zdecydowanie mniejszy. Widoczne jest też, że ekstremalne wartości momentu zginającego $M_{11}$ bez względu na wartość $\eta_{0}$ są prawie identyczne i zlokalizowane w pobliżu brzegu $\eta=0$ (tab. 2). 


\section{Adnotacja}

Niniejsza praca zastała opracowana na podstawie obronionej w 2017 roku na Wydziale Budownictwa i Inżynierii Środowiska SGGW pracy magisterskiej pod tytułem Efekt brzegowy w teorii ptyt średniej grubości, której promotorem był prof. dr hab. inż. Grzegorz Jemielita. Autor pragnie wyrazić wdzięczność profesorowi za jego nieocenioną pomoc w pisaniu pracy.

\section{PIŚMIENNICTWO}

Bolle, L. (1947). Contribution au problème linèaire de flexion d'une plaque èlastique. Bulletin Technique de la Suisse Romande, 73 (22), 293-298.
Jemielita, G. (2002). Coefficients of shear correction in transveresly nonhomogeneous moderately thick plates. Journal of Theoretical and Applied Mechanics, 1 (40), 73-84.

Kaczmarek, K. (2003). Efekt brzegowy w przestrzennych elementach wykonanych z laminatów kompozytowych (praca doktorska). Wrocław: Politechnika Wrocławska.

Konieczny, S. i Woźniak, C. (1967). Obliczanie płyt siatkowych w oparciu o teorię efektu brzegowego. Rozprawy Inżynierskie, 3 (15), 535-551.

Woźniak, C. (1967). Edge effect in lattice-type discs. Bulletin of the Polish Academy of Sciences: Technical Sciences, 1, 21-26.

Woźniak, C. (2001). Mechanika sprężystych ptyt i powtok. Tom VIII. Warszawa: Wydawnictwo Naukowe PWN.

\section{ASSESSMENT OF THE BOUNDARY EFECT RANGE IN HENCKY-BOLLE'S PLATES FOR SELECTED BOUNDARY CONDITIONS}

\section{ABSTRACT}

The present paper analyses the boundary effect in the plate theory. We considered a plate half-band and rectangular plates loaded at the free edge with twisting moments $\hat{m}(\xi)=\frac{\hat{q}_{0} a}{\pi} \cos (\pi \xi)$ and lateral load $\hat{q}(\xi)=\hat{q}_{0} \sin (\pi \xi)$. Such load does not cause displacements or stress resultants in plates calculated according to the thin plate theory. The boundary effect occurs when we analyse plates of medium thickness. The paper obtains solutions according to the Hencky-Bolle theory and it presents the boundary effect in a plate band and rectangular plates. We studied the scope of disturbances caused by the edge load in the half-band as well as the influence of homogenous boundary conditions, given on the opposite edges of rectangular plates, on the scope of the boundary effect. It was shown that the solutions of the half-band and rectangular plates at the $\eta_{0}=\frac{b}{a}=1$ quotient do not differ significantly, and at $\eta_{0}=\frac{b}{a}=2$ the differences disappear, which means that at a distance of two plate widths displacements and stress resultants disappear.

Key words: Kirchhoff plates, Hencky-Bolle plates, boundary effect 